\title{
Leisure boredom and high school dropout in Cape Town, South Africa
}

Lisa Wegner ${ }^{a, b},{ }^{*}$, Alan J. Flisher ${ }^{b, c}$, Perpetual Chikobvud ${ }^{d, e}$, Carl Lombard ${ }^{d}$, Gary King ${ }^{f}$

${ }^{a}$ HIV/AIDS Program, University of the Western Cape, Private Bag X17, Bellville 7535, South Africa

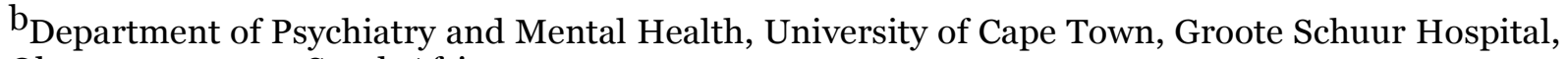
Observatory 7925, South Africa

${ }^{c}$ Research Centre for Health Promotion, University of Bergen, Norway

$\mathrm{d}_{\text {Biostatistics Unit, Medical Research Council, Bellville, South Africa }}$

e Department of Community Health, University of the Free State, P.O. Box 339, Bloemfontein, South Africa

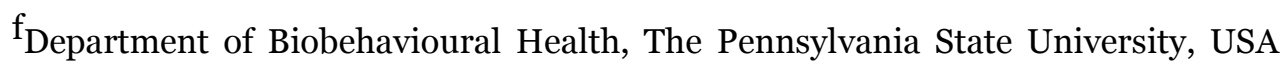

\begin{abstract}
This prospective cohort study investigated whether leisure boredom predicts high school dropout. Leisure boredom is the perception that leisure experiences do not satisfy the need for optimal arousal. Participants completed a self-report questionnaire which included the Leisure Boredom Scale. The original cohort of grade 8 students (n 1/4 303) was followed up twice at 2-yearly intervals. Of the 281 students at the second follow-up, 149 (53.0\%) students had dropped out of school. The effect of leisure boredom on dropout was investigated using logistic regression taking into account the clustering effect of the schools in the sampling strategy, and adjusting for age, gender and racially classified social group. Leisure boredom was a significant predictor of dropout (OR 1/4 1.08; 95\% CI: 1.01-1.15) in students 14 years and older, but not so in younger students (OR 1/4 1.0; 95\% CI: 0.95-1.05). The study has shown that measuring leisure boredom in grade 8 students can help identify students who are more likely to drop out of school. Further research is needed to investigate the longitudinal association between leisure boredom and school dropout.
\end{abstract}

Keywords: Adolescents; High school dropout; Leisure Boredom; Leisure Boredom Scale; South Africa

\section{Introduction}

In South Africa, a major concern in adolescent health and education is school dropout, which is defined as leaving school before completing a given grade in a given school year (Department of Education, 2006). Although as many as 60\% of 
South African children who start school dropout before completing high school (Department of Education, 2003), very little is known about the complexities surrounding the problem.

South Africa has 12.3-million students attending 26,292 schools (South Africa.Info). This figure includes 1098 (4.2\%) registered independent or private schools catering for 340,000 students (2.8\% of the total schooling population). There are about 6000 high schools (grades 7-12) and the rest are primary schools (grades $0-6$ ). There are three recognised levels of education: General Education and Training (GET), Further Education and Training (FET), and Higher Education and Training (HET). Students start school in grade $\mathrm{O}$ and proceed through 13 years of school until grade 12-the final year of schooling. GET runs from grades o to 9. Under the South African Schools Act of 1996, education is compulsory for all South Africans from age 7 (grade 1) to age 15, or the completion of grade 9. FET takes place from grades 10 to 12 , and also includes career-oriented education and training offered in other FET institutions, such as technical, community and private colleges.

Research regarding school dropout has been conducted primarily within the developed world. Apart from being faced with the threat of economic and social difficulties, adolescents who drop-out of school prematurely are at greater risk of behavioural, mental and family disorders, sexual and physical abuse (Franklin, 1992), substance use (Aloise-Young \& Chavez, 2002; Aloise-Young, Cruikshank, \& Chavez, 2002; Fuller et al., 2002; Krohn, Lizotte, \& Perez, 1997; Zimmerman \& Maton, 1992) and involvement in crime (Beauvais, Chavez, Oetting, Deffenbacher, \& Cornell, 1996). In an integrative review of literature, Rosenthal (1998) grouped non-school correlates of dropout into socio-economic status, minority group status, gender, community characteristics, household status, taking adult roles, social support for school staying, family process, student involvement in education, autonomy needs versus social conforming, deviance and personality traits.

Despite the severity of the problem and the resulting burden on society, there has been scant research in developing countries to investigate the dynamics contributing to early school leaving. Flisher and Chalton (1995) investigated the characteristics and risk-taking behaviour of high- school dropouts living in a working-class community in Cape Town, South Africa. They found that adolescents who dropped out of school had higher rates of cigarette and alcohol use compared with those still in school, and that girl dropouts were more likely to engage in sexual intercourse. Of the dropouts, $62.1 \%$ left school after less than 9 years of schooling. However, this study was limited by a small sample size, a crosssectional design, and different methods of data collection for the dropouts and those in school. 
One factor that has not previously been investigated in relation to dropout, is leisure boredom. Leisure boredom is defined as " $y$ the subjective perception that available leisure experiences are not sufficient to instrumentally satisfy needs for optimal arousal" (Iso-Ahola \& Weissinger, 1990, p. 4). Leisure provides many opportunities for positive youth development. Engaging in leisure activities provides adolescents with a context for developing identity, motivation, autonomy and selfregulated behaviour. Furthermore, leisure affords opportunities for personal enrichment and socialisation, and enables adolescents to develop important skills such as decision-making and planning (Caldwell \& Baldwin, 2005; Passmore \& French, 2003). Healthy, or high-yield leisure activities are those that offer a positive experience by allowing for creative engagement with the environment, being goal- oriented and offering appropriate challenges, for example-hiking or photography; as opposed to low-yield activities such as watching television or hanging out which may offer a more negative experience of leisure (Carnegie Council on Adolescent Development, 1992).

Leisure boredom occurs when adolescents' experiences of leisure engagement are less than satisfactory, when their needs are not met by their leisure experiences, when they perceive their leisure activities to be insufficiently challenging, or when they feel that they lack the skills to participate in leisure (Iso-Ahola \& Weissinger, 1990). Boredom which arose primarily from a lack of participation in other activities was a significant motive for male adolescent binge drinking (Ziervogel, Ahmed, Flisher, \& Robertson, 1998). Due partly to their sensation-seeking personalities, adolescent substance-users engaged in more leisure activities but were more likely to experience leisure boredom than nonsubstance abusers (Iso-Ahola \& Crowley, 1991).

There is evidence that leisure boredom among South African adolescents is high. In a recent study of high school students in Cape Town (n $1 / 4$ 621), relatively higher levels of leisure boredom were found among Black adolescents (compared to White adolescents), girls, and younger adolescents (grade 8 compared to grade 11) (Wegner, Flisher, Muller, \& Lombard, 2006). Adolescents living in a socially impoverished area of South Africa had limited opportunities to become involved in leisure activities due to the lack of leisure resources within the environment, and many young people spent their time sitting around or "hanging out" in groups outside and on the streets because they had nothing else to do (Wegner \& Magner, 2002). "Having nothing else to do" and "having to" engage in particular activities are influencing factors in adolescent boredom (Caldwell \& Darling, 1999).

In summary, there is a need for prospective research designs to promote better prediction and understanding of school dropout in the developing world. This is 
particularly so for South Africa, where there is a high rate of school dropout, as well as relatively high levels of leisure boredom among high school students (Wegner et al., 2006). However, there have been no studies locally or internationally that have investigated leisure boredom in relation to school dropout. Therefore, the present study addressed the following research question. Is leisure boredom a predictor of high school dropout among high school students in Cape Town, South Africa?

\section{METHOD}

\section{Sample}

The present study formed part of the South African Community Epidemiology Network on Drug Use (SACENDU): School Study, which was a prospective cohort study of risk behaviour in students from 39 high schools in Cape Town, South Africa (Flisher, Parry, Evans, Muller, \& Lombard, 2003). The original cohort of grade 8 students was first tested in 1997 (Time 1), followed up in 1999 (Time 2), and again in 2001 (Time 3) (Flisher, Evans, Muller, \& Lombard, 2004).

The study population was defined as all students in grade 8 attending public high schools in Cape Town. Schools were stratified according to postal (zip) code areas, and schools were selected such that the proportion of selected schools within a stratum was proportional to the total number of students in that stratum. Within each stratum, the probability of selection of a school was proportional to the number of students in the school. This strategy resulted in the selection of 39 urban schools comprising students from diverse socio-economic (working, middle and upper class) and racially classified social groups (RCSG). The term RCSG derives from the classification system used by the apartheid government, which was described in the Population Registration Act of 1950 and repealed in 1991, that divided the population of South Africa into Black, White, Asian, and Coloured (mixed Asian, European, or African ancestry). The social effects of this Act are still present; therefore, statistics in this study are presented according to RCSG where appropriate.

Forty students were randomly selected from two randomly selected grade 8 classes. This multistage sampling procedure produced a representative sample of 1470 students for the larger SACENDU study. By randomly selecting seven to eight students from every group of forty students, a sub-sample of 303 grade 8 students was obtained who participated in the present study. Students in the sample had a mean age of 14.1 years (S.D. $1 / 41.2$ years); $59.2 \%$ (n $1 / 4171$ ) were female; 49.5\% (n $1 / 4$ 143) were Coloured, 25.6\% (n $1 / 4$ 74) were White, and $24.9 \%$ 
(n $1 / 4$ 72) were Black. These figures exclude 14 missing responses for gender and RCSG.

\section{Procedure}

The Research Ethics Committee, Faculty of Health Sciences, University of Cape Town approved the study. Permission to carry out the study was obtained from the district Education Department and the principals of the selected schools. Students gave their consent to participate and were informed that they had the right to decline to answer any of the questions. The questionnaires were administered during a normal school period, and took approximately $45 \mathrm{~min}$ to complete. Seating was arranged such that confidentiality was ensured. Members of the research team administered the questionnaires with no school staff present. Students were not required to write their names or any other identification details on the questionnaires, thus remaining anonymous. Once they had completed the questionnaire, students copied the unique identifying number of their questionnaire onto a piece of paper which they put into an envelope, sealed, signed across the seal, and wrote their name on the front of the envelope. On follow up at Times 2 and 3, the envelopes were handed back to the students who transferred their identification number onto their new questionnaire. In this way, data were linked while preserving anonymity.

\section{Instrument}

The instrument was a self-report questionnaire consisting of two parts, which students could complete in their preferred language (English, Xhosa or Afrikaans). The questionnaire was translated from English into Xhosa and Afrikaans, and then back-translated by people who had these languages as first languages. Participants completed Parts One and Two of the questionnaire at Time 1, and only Part One at Times 2 and 3 of the data collection phases.

Part One contained items about demographic characteristics (age, gender, RCSG), as well as items about the use of various substances (e.g. tobacco, alcohol, cannabis, mandrax, ecstasy, crack). The substance use variables were not relevant to the present study and have been reported elsewhere (Flisher et al., 2003). Part One of the questionnaires was used previously in a study of 7340 high school students in Cape Town and subjected to extensive pilot studies in small groups and classrooms (Flisher, Ziervogel, Chalton, Leger, \& Robertson, 1993). The test-retest reliability using Cohen's kappa was found to be 0.85 for cigarettes, 0.78 for alcohol and 0.80 for cannabis, while the observed agreement was 0.97 for mandrax, 0.97 for ecstasy and 0.98 for crack (Flisher et al., 2004). 
Part Two of the questionnaire comprised the Leisure Boredom Scale (LBS) (Iso-Ahola \& Weissinger, 1990) which was used to measure "y individual differences in perceptions of boredom in leisure" (Iso-Ahola \& Crowley, 1991, p. 264). The LBS consisted of 16 items, which asked about the quality of leisure experiences (e.g., "For me, leisure time just drags on and on", and "Leisure time is boring"), leisure activities (e.g., "I do not have many leisure activities available to me"), and skills (e.g., "In my leisure time, I usually don't like what I'm doing, but I don't know what else to do"). Subjects responded on a 1-5 Likert scale (1 $1 / 4$ strongly disagree to $5^{1 / 4}$ strongly agree). Total scores could range from 16 (lowest boredom) to 8o (highest boredom) giving a range of 64 points. The questionnaire was used previously with high school students in South Africa (Wegner et al., 2006), and was shown to have a high degree of test-retest reliability (Wegner, Flisher, Muller, \& Lombard, 2002) with Cohen's Kappa in the moderate range for seven items (range: 0.41-0.52) and the fair range for two items (range: 0.32-0.38). The observed agreement was preferred for seven items (range: $38.8-66.6 \%$ ). The concordance correlation on the LBS was 0.73 using a 95\% confidence interval (o.64-0.82). Cronbach's alpha coefficient was 0.76. For the translated questionnaires, Cronbach's alpha was 0.78 for the English version, 0.81 for the Afrikaans version, and 0.57 for the Xhosa version.

\section{Analysis}

Descriptive statistics for school dropout according to LBS score categories (040, 40 to $050,50+$ ), gender, RCSG and age were obtained. Students who had missing answers for two or less items on the LBS (n 1/4 95) were assigned a score of 1 (being the most conservative score) for the missing items in order to calculate an overall leisure boredom score for them. The outcome dependent) variable was coded as one of two outcomes: in-school or dropped out. The in-school group included students who completed questionnaires at Times 1 and 3; students who were absent at Time 3 but still attending school; those who had moved to another city or transferred to another school; and those who graduated in 2001 or 2002. Students for whom there was any doubt about their school status were included in the in-school group. The dropout group included those students who were known to have left school after the administration of the questionnaire at Time 1 and before Time 3; those not completing the questionnaire at Time 2 who could not be traced, who remained absent at Time 3, and who did not graduate in the Western Cape in 2001 or 2002; and students who were untraceable at Time 3 who did not graduate in the Western Cape in 2001 or 2002.

The effect of leisure boredom on dropout was modelled using logistic regression 
taking into account the cluster effect of the schools in the sampling strategy, and adjusting for gender, RCSG, and student age at recruitment (coded as younger than 14 years or, 14 years or older).

\section{RESULTS}

A total of 303 grade 8 students completed the questionnaire at Time 1. Of the 281 students whose dropout status could be ascertained at Time 3, 149 (53.0\%) were regarded as having dropped out of school and the remaining 132 (47.0\%) were regarded as being in-school. Descriptive statistics for school dropout stratified by LBS score categories; gender, RCSG and age are indicated in Table 1. Overall dropout rates were similar for lower LBS scores (040) and moderate LBS scores (40 to 050 ) being $50.6 \%$ and $51.4 \%$, respectively, and increased to $61.1 \%$ for higher LBS scores $(5 \mathrm{O}+)$. In other words, there was a relatively higher dropout rate among students who reported greater boredom with leisure time. Dropout rates were higher among boys (61.1\%), Black students (60.6\%) and students aged 14 years or older (64.9\%).

The smoothed dropout prevalence for the range of LBS scores is shown in Fig. 1. The J-shaped curve was investigated, and evidence of a modification effect of age emerged in Fig. 2 where the Fig. 2. Dropout prevalence for Leisure Boredom Scale scores by age group and gender. Cohort is split by age group and gender. This was formally investigated and the odds ratios estimated from the logistic regression model are given in Table 2. There was a significant interaction between age group of the student and leisure boredom (p 1/4 0.03). Leisure boredom was a significant predictor of dropout (OR $1 / 4$ 1.08; 95\% CI: 1.01-1.15 for a unit change on the scale) in students 14 years and older, but not so in younger students (OR $1 / 4$ 1.0; 95\% CI: 0.95-1.05) (p 1/4 0.85), when adjusting for RCSG and gender, and taking into account the clustering effect of the schools.

The age specific models for dropout on leisure boredom are also given in Table 2. In the overall model with the age-leisure boredom interaction term there was a significant gender effect, with female students having a smaller odds for dropout (OR 1/4 0.55; 95\% CI: 0.33-0.91) (p 1/4 0.02). 
Table 1

School dropout rates stratified by Leisure Boredom Scale (LBS) score categories, gender, RCSG and age $(n=281)$

\begin{tabular}{|c|c|c|}
\hline & In-school & Drapor: \\
\hline & 和 & * \\
\hline 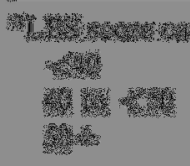 & 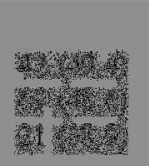 &  \\
\hline $\begin{array}{l}\text { Cowatex } \\
\text { Nale } \\
\text { Female }\end{array}$ & $\begin{array}{l}42(36.9) \\
39(52.7)\end{array}$ & $\begin{array}{l}6(61.1) \\
20(47.3)\end{array}$ \\
\hline $\begin{array}{l}\text { ReSG } \\
\text { Black } \\
\text { Coloured } \\
\text { White }\end{array}$ & $\begin{array}{l}26(39.4) \\
73(54.1) \\
33(45.2)\end{array}$ & $\begin{array}{l}40(60.6) \\
62(45.9) \\
40(54.8)\end{array}$ \\
\hline 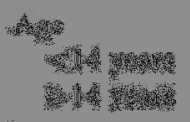 & $\begin{array}{l}1 \\
1 \\
1\end{array}$ & 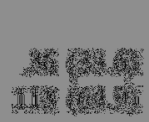 \\
\hline
\end{tabular}


L. Wegner et al. / Jownal of Adolescence 31 (2008) $421-431$

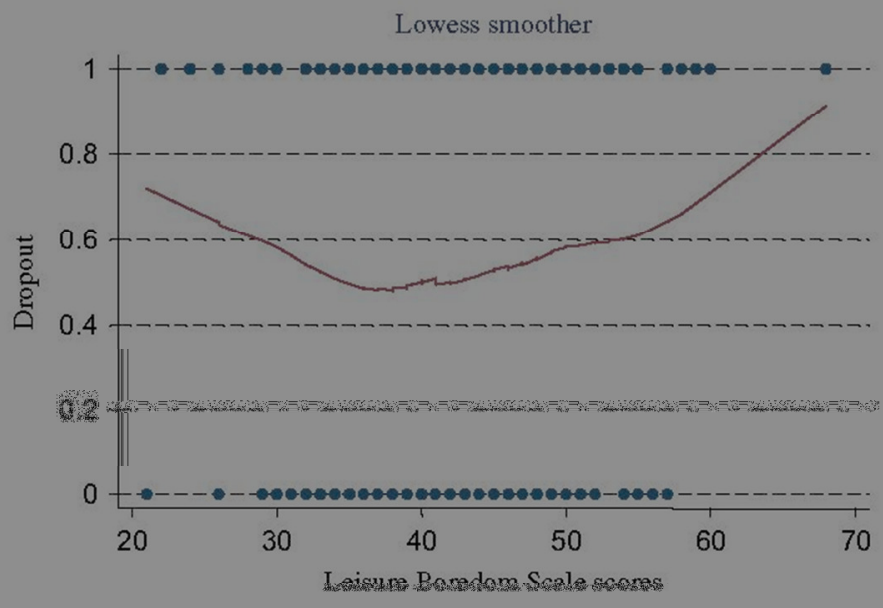

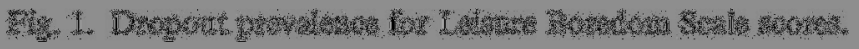

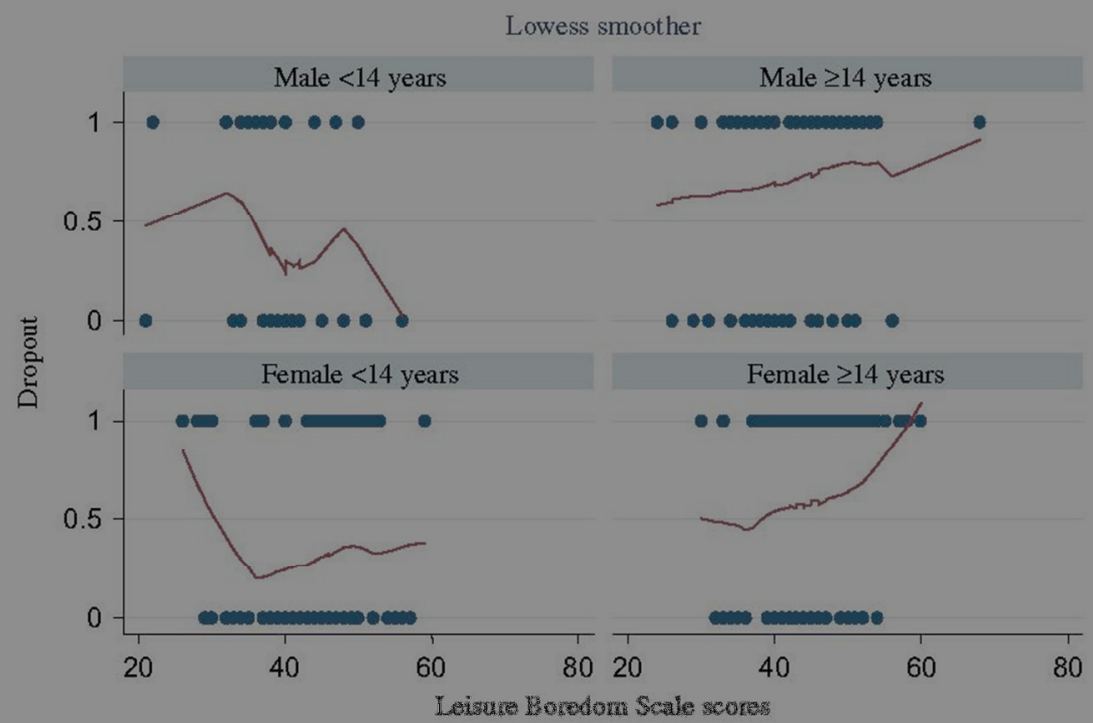

Fig. 2. Dropout prevalence for Ieisure Boredom Scale scores by age group and geader.

Examination of the age specific models showed that the gender effect in the younger group was not that marked and also not significant. However, in the older student group gender was a significant factor and also more marked than in the overall model. A model (results not shown) with a gender and age interaction term added, strengthened the association between dropout and leisure boredom in the older group of students (OR 1/4 1.09; 95\% CI: 1.02-1.17).

\section{DISCUSSION}

To our knowledge, this is the first study in the world to investigate leisure 
boredom and high school dropout using a longitudinal design. The study has shown that leisure boredom is a predictor of dropout among older students in the grade 8 cohort that was sampled. The older students for this grade are known be at higher risk for dropout, and the level of boredom in this higher risk group can be used to identify students who are more likely to dropout during the next 4 years of school. In the younger stratum of this cohort, leisure boredom was not a significant predictor of dropout. These findings raise the question whether leisure boredom will be predictive of dropout in older students but who are not old for their grade. These results must also be considered against the high level of dropout overall in this cohort. Further research is needed to investigate modification effects of age on the predictive performance for high school dropout of the LBS.

Students who reported a higher level of boredom in their leisure time may have been experiencing boredom with other components of, and activities in their lives, such as school.

Research evidence shows that adolescents who reported high levels of boredom in school also experienced boredom with out-of-school activities such as leisure (Larson \& Richards, 1991; Shaw, Caldwell, \& Kleiber, 1996). Thus, students who feel more bored in their leisure time may be at greater risk of dropping out of school due to their perception of school as being boring. This may be due to disliking certain subjects or teachers, not seeing the relevance of subjects, and feeling either understimulated or overwhelmed by subject content and requirements. In schools where there are limited, or no after-school, extracurricular sport and leisure activities (such as the case in many poorer schools in South Africa) the experience of boredom both within and after school may be compounded. The adolescent may feel disconnected from the school, making dropping out of school easier.

Perceiving school as boring may also be a result of adolescent resistance to adult control and authority (Larson \& Richards, 1991). Adolescents may respond through passive non-participation in school activities, which feeds into the cycle of under stimulation and boredom. Ultimately, this may lead to the adolescent dropping out of school. Further research needs to be done among South African adolescents on the experience of boredom at school.

The present study has certain limitations. First, the sample was limited to schoolgoing adolescents in Cape Town, an urban part of South Africa. Thus, we do not know the extent to which the results are generalisable to adolescents living in other parts of the country or in rural areas. Second, the LBS was the only measure of adolescents' leisure experiences used in the study. Although this instrument has 
satisfactory psychometric properties in the Cape Town setting (Wegner et al., 2002) and has been used elsewhere in the world (Iso-Ahola \& Crowley, 1991; IsoAhola \& Weissinger, 1990), the inclusion of other measurements may have provided a more comprehensive understanding of adolescents' experiences of leisure and boredom. Third, although every effort was made to confirm the dropout status of students thus classified, without this confirmation coming from the students themselves, or members of their families, some misclassification may have occurred. However, where there was doubt as to whether the student had dropped out, the student was included as still being in school. Thus, if there was any misclassification bias, it was likely to result in an underestimation of the effects of leisure boredom. Fourthly, with the present sample size (n $1 / 4281$ ), we were not able to extend the model to investigate mediating or moderating factors such as substance use in the analysis of the relation between leisure boredom and dropout, or test for interactions. The association between high school dropout, and substance use (Flisher, Townsend, Chikobvu, Lombard, \& King, 2004), and sexual risk behaviour (Flisher, Townsend, Chikobvu, Lombard, \& King, 2005) has been reported. However, there is a need for further research to investigate interactions between different variables and the complexities around high school dropout.

Tentative implications for practice at this point are that schools have a responsibility to implement strategies for addressing leisure boredom at high schools as part of the response to school dropout. For those students with high leisure boredom, the aim should be to reduce boredom through strategies that encourage exploration and participation in leisure, sport and recreational activities both during and after school. This is especially important in schools where after-school sport and leisure activities are limited or non-existent. Often this is the case for schools situated in poorer areas.

In conclusion, the present study has broken new ground in that it is the first cohort study in the world to examine leisure boredom as a predictor of school dropout. As such, it contributes to our knowledge of adolescent leisure boredom and our understanding of high school dropout in South Africa. Leisure boredom should be considered as part of the complex factors contributing to high school dropout. However, the situation is complicated and we need to understand it better. There is a need to examine further, the longitudinal association between leisure boredom and school dropout.

\section{Acknowledgements}

The authors would like to thank the principals, staff and students of the participating schools, and Janet Evans for co-ordinating the data collection. The 
study was funded by the World Health Organisation Programme on Substance Abuse, the United Nations Development Programme, the Health Professions Council of South Africa, and the Universities of Cape Town and the Western Cape. 


\section{References}

Aloise-Young, P. A., \& Chavez, E. L. (2002). Not all school dropouts are the same: Ethnic differences in the relation between reason for leaving school and adolescent substance use. Psychology in Schools, 39, 539-547.

Aloise-Young, P. A., Cruikshank, C., \& Chavez, E. L. (2002). Cigarette smoking and perceived health in school dropouts: A comparison of Mexican American and non-Hispanic white adolescents. Journal of Pediatric Psychology, 6, 497-507.

Beauvais, F., Chavez, E. L., Oetting, E. R., Deffenbacher, J. L., \& Cornell, G. R. (1996). Drug use, violence, and victimization among white America, Mexican American and American Indian dropouts, students with academic problems and students in good academic standing. Journal of Counseling Psychology, 43, 292299.

Caldwell, L. L., \& Baldwin, C. K. (2005). A developmental approach to understanding constraints to adolescent leisure. In E. Jackson (Ed.), Constraints to leisure. State College, PA: Venture.

Caldwell, L. L., \& Darling, N. (1999). Leisure context, parental control, and resistance to peer pressure as predictors of adolescent partying and substance use: An ecological perspective. Journal of Leisure Research, 31, 57-77.

Carnegie Council on Adolescent Development. (1992). Task force on youth development and community programs. A matter of time: Risk and opportunity in the nonschool hours. Washington, DC: Author.

Department of Education. (2003). Education statistics in South Africa at a glance in 2001. Pretoria: South Africa.

Department of Education. (2006). Minister of education rejects report on school drop-out rates (25 July 2006).http:// www.info.gov.za/speeches/2006/06072608151001.htmS; accessed 10.08.07.

Flisher, A. J., \& Chalton, D. O. (1995). High-school dropouts in a working-class South African community: Selected characteristics and risk-taking behaviour. Journal of Adolescence, 18, 105-121.

Flisher, A. J., Evans, J., Muller, M., \& Lombard, C. L. (2004). Test-retest reliability of self-reported adolescent risk. Journal of Adolescence, 27, 207-212. 
Flisher, A. J., Parry, C. D., Evans, J., Muller, M., \& Lombard, C. (2003). Substance use by adolescents in Cape Town: Prevalence and correlates. Journal of Adolescent Health, 32, 58-65.

Flisher, A.J., Townsend, L., Chikobvu, P., Lombard, C., \& King, G. (2004, 6-10 November). Relationship between substance use and high school dropout in Cape Town, South Africa. Paper presented at the 132nd annual meeting of the American Public Health Association. Washington, DC.

Flisher, A.J., Townsend, L., Chikobvu, P., Lombard, C., \& King, G. (2005, 8-23 October). Sexual behaviour and high- school dropout in South Africa. Paper presented at the 52nd annual meeting of the American Academy of Child and Adolescent Psychiatry and 25th annual meeting of the Canadian Association of child and adolescent psychiatry. Toronto, Canada.

Flisher, A. J., Ziervogel, C. F., Chalton, D. O., Leger, P. H., \& Robertson, B. A. (1993). Risk-taking behaviour of Cape Peninsula high-school students. Part I: Introduction and methods. South African Medical Journal, 83, 469-473.

Franklin, C. (1992). Family and individual patterns in a group of middle-class dropout youths. Social Work, 37, 338-344.

Fuller, C. M., Vlahov, D., Ompad, D. C., Shah, N., Arria, A., \& Strathdee, S. A. (2002). High-risk behaviours associated with transition from illicit non-injection to injection drug use among adolescent and young adult drug users: A casecontrol study. Drug and Alcohol Dependence, 66, 189-198.

Iso-Ahola, S. E., \& Crowley, E. D. (1991). Adolescent substance abuse and leisure boredom. Journal of Leisure Research, 23, 260-271.

Iso-Ahola, S. E., \& Weissinger, E. (1990). Perceptions of boredom in leisure: Conceptualisation, reliability and validity of the Leisure Boredom Scale. Journal of Leisure Research, 22, 1-17.

Krohn, M. D., Lizotte, A. J., \& Perez, C. M. (1997). The interrelationship between substance use and precocious transitions to adult statuses. Journal of Health and Social Behaviour, 38, 87-103.

Larson, R. W., \& Richards, M. H. (1991). Boredom in the middle school years: Blaming schools versus blaming students. American Journal of Education, 99, 
$418-443$.

Passmore, A., \& French, D. (2003). The nature of leisure in adolescence: A focus group study. British Journal of Occupational Therapy, 66, 419-426.

Rosenthal, B. S. (1998). Non-school correlates of dropout: An integrative review of literature. Children and Youth Services Review, 20, 413-433.

Shaw, S. M., Caldwell, L. L., \& Kleiber, D. A. (1996). Boredom, stress and social control in the daily activities of adolescents. Journal of Leisure Research, 28, 274293.

SouthAfrica.Info. Education in South Africa. /http://www.southafrica.info/ess_info/sa_glance/education/educa- tion.htmS; accessed 10.08.07.

Wegner, L., Flisher, A. J., Muller, M., \& Lombard, C. (2002). Reliability of the Leisure Boredom Scale for use with high school students in Cape Town. Journal of Leisure Research, 34, 340-350.

Wegner, L., Flisher, A. J., Muller, M., \& Lombard, C. (2006). Leisure boredom and substance use among high school students in South Africa. Journal of Leisure Research, 38, 249-266.

Wegner, L., \& Magner, I. (2002, 23-28 June). Is leisure an occupational concern? Understanding leisure in adolescents.

Paper presented at the $13^{\text {th }}$ world congress of occupational therapists. Stockholm, Sweden.

Ziervogel, C. F., Ahmed, N., Flisher, A. J., \& Robertson, B. A. (1998). Alcohol misuse in South African male adolescents: A qualitative investigation. International Quarterly of Community Health Education, 17, 25-41.

Zimmerman, M. A., \& Maton, K. I. (1992). Life-style and substance use among male African-American urban adolescents: A cluster analytic approach. American Journal of Community Psychology, 20, 121-138. 